\title{
About the Causes of the Koror Bridge Collapse
}

\author{
Corneliu Bob \\ University "Politehnica” of Timisoara, Timisoara, Romania \\ Email: cbob@mail.dnttm.ro
}

Received 26 April 2014; revised 25 May 2014; accepted 23 June 2014

Copyright (C) 2014 by author and Scientific Research Publishing Inc.

This work is licensed under the Creative Commons Attribution International License (CC BY). http://creativecommons.org/licenses/by/4.0/

c) (i) 0pen Access

\section{Abstract}

This paper has been prepared from basic works published, mainly, after 2008 when the collapse investigation was made available. The main contributions of the paper are: a proper model for the deflections at mid-span of the bridge, the state of stress in elastic and post elastic stage for same phases of behavior, the stage of cracked of the top of cantilever beams, the repair effect on the structure of Koror Bridge, the probabilistic evaluation. The present study is based on well known and simple engineer tools: the one-dimensional beam-type was analyzed.

\section{Keywords}

Koror Bridge, Collapse, Causes, Cantilevers, Continuous Girder, Prestressed Concrete, State of Stress, Deflection, Stiffness Reduction, Probabilistic Evaluation

\section{Introduction}

The target of the work is to establish main causes, in the author conception, of the Koror Bridge collapse (Figure 1).

The analysis is based on the data offered by sources published, around and after 2008 when the collapse investigation was made available [1]-[4]. The most complete work is "The story of the Koror Bridge" by ManChung Tang, in which he said "Learning from our mistakes is especially useful, as it can teach us what can be done and what cannot be done. But, for the past to be useful, we must carefully and honestly present the facto".

The engineering community often considers the study of such major collapse as an opportunity to correct and improve on future design, as T. Galambos noted [5].

On the other hand, Prof. Bazant introduced a resolution to the Structural Engineers World Congress (Bangalore, Nov. 6, 2007), in which he pointed "the structural engineers believe that the release of all technical data 


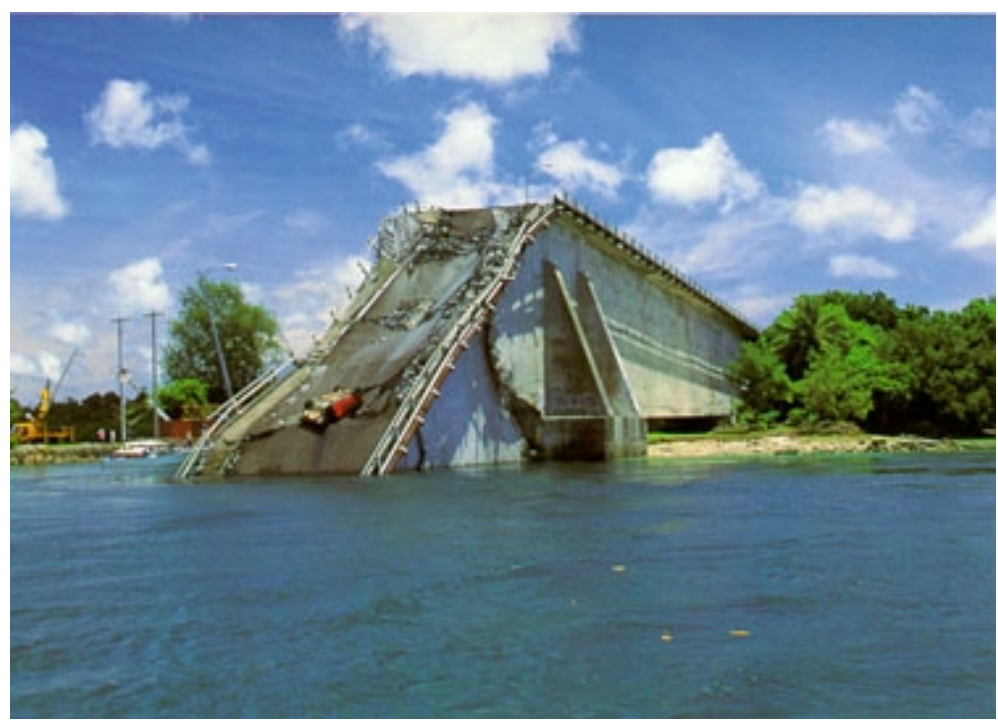

Figure 1. The Koror Bridge collapse.

would likely lead to progress in structural engineering and possibly prevent further collapses of large concrete structures” [3].

The analysis started from the questions raised after the collapse, noted by M.-C. Tang [1]: Why was deflection so much larger than that anticipated? What would happen if there were no repairs? What did the repair change in the structure? Why did the slab of the Babeldaob cantilever near the main pier crushed and initiate the collapse? There are, too, additional problems concerning the Koror Bridge collapse: the structure system with two cantilevers for the bridge; the class of concrete used; the arrangement of tendons in the top slab near main pier; the character of partial prestressed elements of the two cantilever beams.

The present work focused on such questions and the answers are based on well known and simple engineer tools. The one-dimensional beam-type analysis was used, even it was considered to lead to great errors in deflection as well as prestress loss [3]. The results of the analysis are very close to experimental measurements. The original aspects of the present study are: a proper model for the deflections at mid-span of the bridge, the state of stress in elastic and post elastic stage for some phases of behaviour, the stage of cracked of the top of cantilever beams, the repair effect on the structure of Koror Bridge, the probabilistic evaluation.

\section{The Deflection}

The mid-span total deflection was a subject debated by many authors.

In the Table 1 and Figure 2, deflection at mid-span under various assumption presented by Man-Chung Tang are given.

Figure 2, proposed by the author of this work, is an illustration of the deflection due to different factors (prestress, elastic behaviour, creep influence). The last column in the Table 1 is the author proposal for the total deflection at mid-span.

The assumption started from the test results (column 3): the prestress loss is $50 \%$. Calculation of total elastic deflection assumes a reduce girder stiffness by $50 \%$ as compared whit initial design. The creep deflection was obtained from positive deflection by introduction of modified elasticity modulus $E^{\prime}$ with formula [6]:

$$
E^{\prime}=\frac{0.8 \cdot E}{1+0.5 v \cdot \bar{\varphi}}
$$

where: $E$ —elasticity modulus (Young modulus);

$$
v=\frac{q_{d}}{q}=0.9
$$

$q_{d}$ — sustained loads and $q$ — total loads 


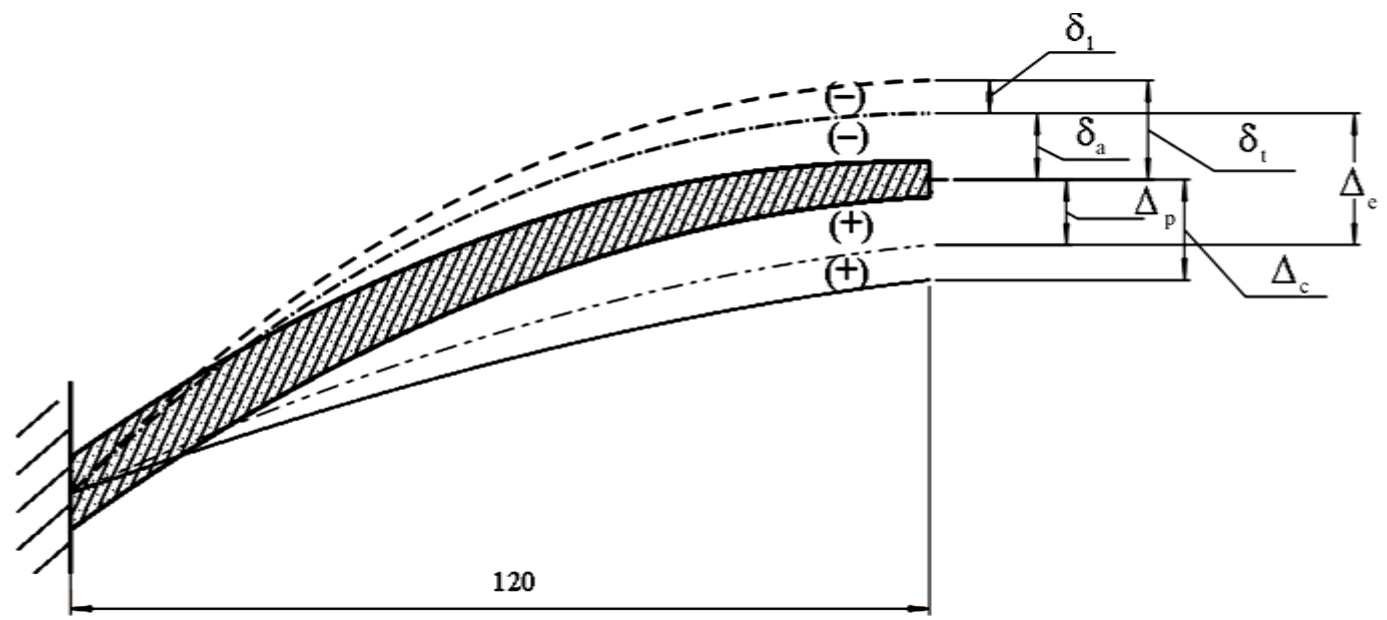

Figure 2. Deflections due to different factors.

Table 1. Deflections at mid-span of the bridge.

\begin{tabular}{|c|c|c|c|c|}
\hline \multirow{2}{*}{$\begin{array}{l}\text { Deflection }[\mathrm{mm}] \\
\text { due to: }\end{array}$} & \multicolumn{3}{|c|}{ Man-Chung Tang } & \multirow{2}{*}{ Corneliu Bob } \\
\hline & Initial design & $\begin{array}{l}\text { Test } \\
\text { results }\end{array}$ & ${ }^{*} 50 \%$ stiffness reduction & \\
\hline 1 & 2 & 3 & 4 & 5 \\
\hline Full prestress $\delta_{t}$ & -761 & -1099 & -2198 & -1100 \\
\hline Prestress loss $\delta_{\mathrm{l}}$ & $\begin{array}{c}+76 \\
(10 \%)\end{array}$ & $\begin{array}{l}+550 \\
(50 \%)\end{array}$ & $\begin{array}{l}+1100 \\
(50 \%)\end{array}$ & $\begin{array}{l}+550 \\
(50 \%)\end{array}$ \\
\hline Prestress active $\delta_{a}$ & -685 & -549 & -1098 & -550 \\
\hline Total elastic deflection $\Delta_{e}$ & +1055 & +1532 & +3064 & $+2030^{*}$ \\
\hline Positive deflection $\Delta_{p}=\Delta_{e}-\delta_{a}$ & +370 & +983 & +1966 & +1470 \\
\hline $\begin{array}{l}\text { Creep deflection } \\
\qquad \Delta_{c}=\varphi . \quad \Delta_{p}\end{array}$ & $\begin{array}{c}+481 \\
(\varphi=1.3)\end{array}$ & $\begin{array}{c}+1573 \\
(\varphi=1.6)\end{array}$ & $\begin{array}{c}+3146 \\
(\varphi=1.6)\end{array}$ & $+3060^{* *}$ \\
\hline Final deflection after correction (20\%) & +385 & +1258 & +2516 & +2450 \\
\hline
\end{tabular}

Notes: ${ }^{*}-50 \%$ stiffness reduction; ${ }^{* *}-E^{\prime}=0.48 \times E$.

$$
\bar{\varphi}=k_{1} \cdot k_{2} \cdot k_{3} \cdot \varphi_{0}=1.46,
$$

where:

$\varphi_{0}$ is the creep coefficient ( $\varphi_{0}=2.6$ for C32/40);

$k_{1}=0.5$ represents the influence of concrete age ( $t>180$ days);

$k_{2}=1.6$ is the influence of the stress in concrete $\left(2 f_{c} / f_{c m}\right)$;

$k_{3}=0.7$ is the influence of the relative humidity $(\mathrm{RH}=90 \%)$.

The final deflection, taking into account creep deflection before closure (assumed 20\% [1]), is about $2.43 \mathrm{~m}$. It is the same with the extrapolation of measured deflection at 36,500 days (100 years), of $\Delta_{\exp }=2.4 \mathrm{~m}$ [1].

On the other hand, for the ultimate limit states, which may require consideration which include, among others, “excessive deformation”, is stipulated a maximum deflection as:

$\Delta_{\max }=\frac{L}{50}=\frac{120}{50}=2.4 \mathrm{~m}$ for a prestressed cantilever element;

$\Delta_{\max }=\frac{L}{100}$ for simple supported prestressed beams;

$\Delta_{\max }=\frac{L}{25}$ for a RC cantilever element; 
$\Delta_{\max }=\frac{L}{50}$ for a RC simple supported beam,

where $L$ is the span of the element.

It can be seen a good correlation between the three values: calculated deflection, extrapolation of measured deflection and excessive deflection. In such circumstances there is possible to have a mean service life of 100 years (1977-2077); by probabilistic evaluation, the fractiles are 67.1 years and 133 years, where $c_{v}=20 \%$.

By application of the before assumption formula (1), to the initial design, the final deflection after correction will results as $6167 \mathrm{~mm}$ which is larger than anticipated, but is still smaller than measured deflection.

Data from Table 1 demonstrated that the main factor of the larger deflection than anticipated is prestress loss which acts with two parameters: diminishes of the counter-deflection and stiffness reduction. In such circumstances, the analysis of the contribution of the creep and shrinkage on the Koror Bridge deflection as main factors of influence are of scientific interesting but not useful for judgment of Koror Bridge behaviour. The creep and shrinkage are still not fully elucidated theories but for practical analysis of the concrete structures (including deflections) the data offered by actual norms and models are today good enough. The results presented in Table 1 are not confirmed by the statement as "The one-dimensional beam-type analysis leads to great errors in deflections as well as prestress loss" [3]. A similar conclusion for stresses, with data presented in Table 1 was found in [2] ".. there are small changes in the stresses from those predicted by simple beam theory as compared whit a three-dimensional finite element built using 20-node brick elements”.

\section{State of Stress}

Explanation of the collapse in the slab cantilever near the main pier by concrete crushed was possible by analysis of the stress distribution. This paper has the focus of attention the stress in compression zone of the main cross-section near the pier because the collapse was initiated in these two zones of the bridge; the tension zone is more safety (see point 5). For the analysis, the critical cross-section near the main pier was taken into account (Figure 3) [3]. The analyzed phases were-the initial phase, the phase with prestress loss, the rehabilitated phase and the final phase before collapse.

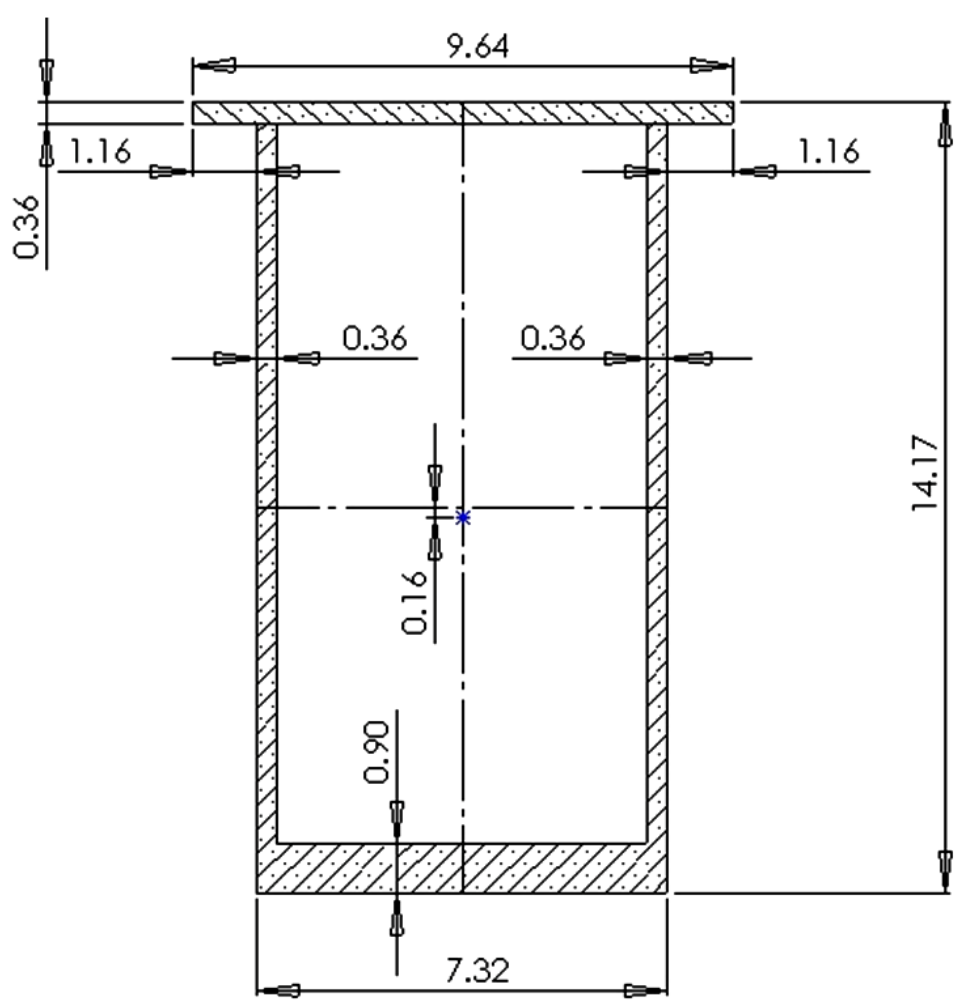

Figure 3. Cross-section near the main pier. 
Under ultimate conditions the bending moment due to permanent loading and the total shear force were appreciated as actual bending moment $M_{g}=1800 \mathrm{MN} \cdot \mathrm{m}$ and the shear force as $V_{g}=34 \mathrm{MN}$; the mean cylinder strength was found $f_{c m}=35 \mathrm{MPa}$ [1].

The prestressing system consists of 300 tendons with the diameter of a bar, $\varnothing=32 \mathrm{~mm}$ and the ultimate strength of $f_{u}=1050 \mathrm{MPa}$. Maximum allowable stress of the tendons during stressing was $0.8 f_{u}$ and $0.7 f_{u}$ after anchoring and before losses the ultimate tension capacity of all 300 bar tendons in the top slab was: $241 \mathrm{MN}$ for $f_{u}, 200 \mathrm{MN}$ for $0.8 f_{u}, 180 \mathrm{MN}$ for $0.7 f_{u}$ and $100 \mathrm{MN}$ for $0.4 f_{u}[1]$.

The initial phase with full prestress $\left(0.8 f_{u}\right)$ is presented in Figure 4, where the external actions are: bending moments due to permanent loading; the prestress force $P_{0}=200 \mathrm{MN}$ and shear forces.

The cross-section has maximum values at the bottom slab $f_{c}=-15 \mathrm{MPa}$. At the top of slab there compression stress of $-5.5 \mathrm{MPa}$ for the actual bending moment.

The shear is also presented in Figure 4, with the maximum value $\tau_{c}=3.35 \mathrm{MPa}$; main tension stresses for $\tau=3.35 \mathrm{MPa}$ resulting are: $\sigma_{1}=-11.32 \mathrm{MPa}, \sigma_{2}=+1.00 \mathrm{MPa}$ and no inclined cracks will appear.

The phase with prestress loss of $50 \%\left(0.4 f_{u}\right)$, as it was measured by experimental determinations, is illustrated in Figure 5.
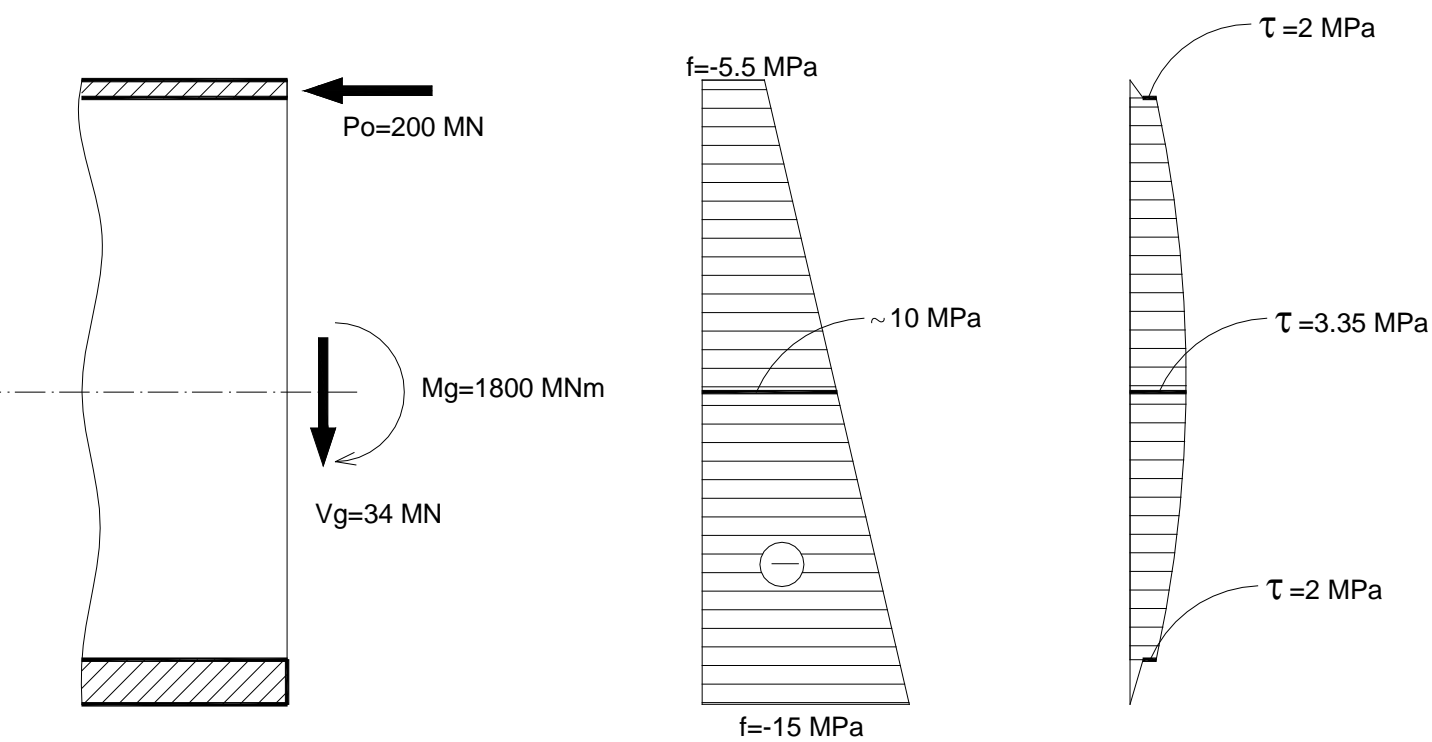

Figure 4. Elastic analysis of initial phase with full prestress.
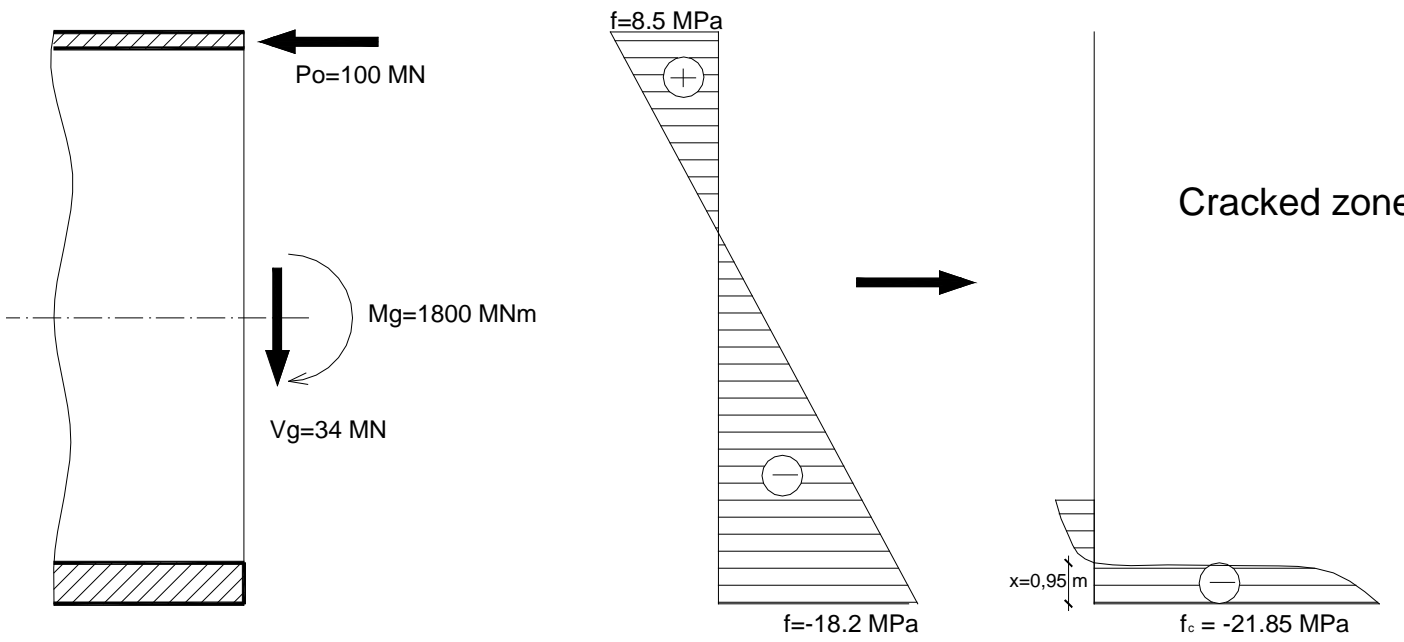

Figure 5. The phase with prestress loss. 
The cause of such prestress loss was, maybe, as it was pointed in [2] “ $\ldots$ the top flange and the web to have been particularly congested with longitudinal, transverse and vertical prestressing tendons crossing one another as well as anchorages for the various tendons". In addition to it the top flange was cracked from the early stage of using of the bridge.

The state of stress obtained with the entire cross-section gives a tension zone at the top of the slab with a values $f_{c}=8.5 \mathrm{MPa}$. In such circumstances, the beam will crack and state of stress of the cross-section near the centerline pier is also illustrated in Figure 5. For this phase, the inclined cracks are not imminent to appear because of small value of main stress $\sigma_{2}^{\max }=+3.35 \mathrm{MPa}$ and the strength to inclined main stress is $R_{f} \cong 2 f_{c r}=7.4 \mathrm{MPa}>3.35 \mathrm{MPa}$. The pattern of cracks (with vertical crack near the main pier) is a confirmation of the diagrams illustrated in Figure 5 and data concerning stresses from Table 2.

The compressed zone is restricted on $0.95 \mathrm{~m}$ (bottom portion of box girder) and the stresses are high: $f_{c}=$ 21.85 MPa.

The quality of concrete was of inferior class, even in practice of that period it was obtained as a good concrete.

The potential value of stress at the top of cross-section for different prestress forces applied at the top slab is presented in Figure 6 (from elastic analysis). It can be concluded: the cracking strength of $f_{c r}=3.79 \mathrm{MPa}$ is attended at a prestress force smaller than $200 \mathrm{MN}\left(0.8 f_{u}\right)$ at $135 \mathrm{MN}\left(0.56 f_{u}\right)$ for actual bending moment; a cracked zone in the early phase with smaller prestress is presented.

\section{The Repair}

The repair changed the bridge into continuous girder by jacking force (27 MN) at the hinge and by applied external tendons inside the box girder (34.7 MN); total force $P_{r}=61.7 \mathrm{MN}$ (Table 2).

The actions of jacking force and external tendons have two effects:

1) A diminution of the stress on the bottom slab of critical cross-section (a reduce girder area by $50 \%$ was assumed) with about $30 \%$ which means a "discharge" of the cantilever beams. The stress on the compression zone would be $f_{c}=-15.15 \mathrm{MPa}$, Table 2 (line No.1).

2) Change the bridge from two cantilever elements into continuous girder which are acted by $30 \%$ of permanent loading, some variable vertical loads and corresponding (30\%) of prestressing force (Table 2). The forces acting on cross-section are: $P_{0}=30.0 \mathrm{MN}, M_{g}=21.6 \mathrm{MNm}, V_{g}=12.0 \mathrm{MN}$ and $H=26.7 \mathrm{MN}$. The state of stress of this phase, as well as final stress in the critical cross-section for continuous structure, are presented in

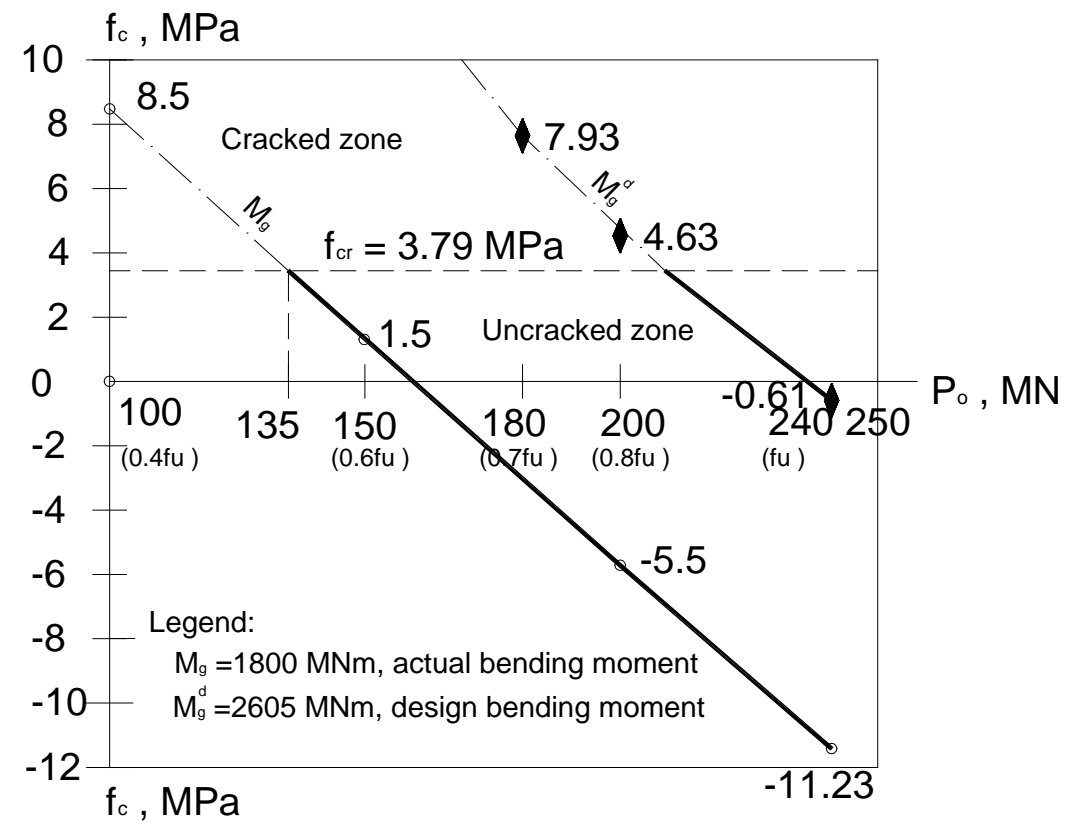

Figure 6. The correlation of potential tension stress v. prestress force at the top slab. 
Table 2. The stresses for different phases.

\begin{tabular}{|c|c|c|c|c|c|}
\hline \multirow{3}{*}{ No } & \multirow{3}{*}{ The phases } & \multirow{3}{*}{ Forces on cross-section } & \multicolumn{3}{|c|}{$\begin{array}{l}\text { Stresses } \\
\text { [MPa] }\end{array}$} \\
\hline & & & \multicolumn{2}{|c|}{ Elastic stage } & \multirow{2}{*}{$\begin{array}{l}\text { Post-elastic stage at bottom slab } \\
\text { (cracked zone) }\end{array}$} \\
\hline & & & Top & Bottom & \\
\hline 0 & 1 & 2 & 3 & 4 & 5 \\
\hline 1 & Rehabilitated phase for cantilever beam & $P_{r}=61.7 \mathrm{MN}$ & -14.10 & +6.70 & -15.15 \\
\hline 2 & $\begin{array}{l}\text { Rehabilitated phase for continuous } \\
\text { structure }\end{array}$ & $\begin{array}{c}P_{0}=30.0 \mathrm{MN} \\
M_{g}=21.6 \mathrm{MNm} \\
V_{g}=12.0 \mathrm{MN} \\
H=26.7 \mathrm{MN}\end{array}$ & -3.37 & -2.50 & -17.65 \\
\hline 3 & Final phase before collapse & $\begin{array}{c}P_{0}=0 \\
M_{g}=1800 \mathrm{MNm} \\
V_{g}=34.0 \mathrm{MN}\end{array}$ & - & - & -25.00 \\
\hline
\end{tabular}

Table 2 (line No.2).

As it was presented some horizontal forces are presented and have to act on the main and secondary piers: the thrust of bridge arch (arch effect) of $H=26.7 \mathrm{MN}$ (Table 2); jacking force of $27 \mathrm{MN}$.

The result of such forces is the moving of two parts of bridge and transformation of continuous girder in the initial status. The settlement of the two bridge parts was produced in time (maybe 2 - 3 months) and only few millimeters of moving in horizontal direction will disturb the continuity of the girder at the hinge.

A similar conclusion was presented in [2] “... the new continuity joint will open up at the bottom because there was nothing to resist to tension. This would have restored the structure to its original configuration of two independent cantilevers".

This fact will change the state of stress as it is presented in Table 2 (line No.3). The maximum compression stress is $25 \mathrm{MPa}$ for the actual bending moment; no prestress force $P_{0}$ was taken into account.

The repair provides a balanced state of stress but the measures were insufficient; a system to keep together the slab decks at the hinge, have been necessary.

\section{Probabilistic Evaluation}

The collapse evaluation of the Koror Bridge is based on the theory of structural reliability where the variables involved are considered to be random. Safety is expressed in terms of the Probability of Failure, $P_{f}$, instead of the safety factor typical of a deterministic evaluation.

Statistical definition of the variables the resistance material and of the action effects were considered with the same values and distribution as:

-coefficient of variation: $c_{v}^{r}=c_{v}^{a}=20 \%$;

-type of distribution: Normal;

-fractiles (characteristic values) for a probability of $5 \%$.

The high value of the coefficient of variation was taken due to many problems which had characterized the bridge: concrete class, prestressed loss, presence of cracks, large deflections etc. The representative values of the stresses are presented in Table 3.

Table 3 shows the main results obtained on the compressed stress of the concrete and the tensile stress of the reinforcement (bar tendons) on the critical cross-section of the bridge by using probabilistic evaluation. From deterministic evaluation there is a safety behaviour, even the global safety factor $c_{0}$ is slightly superior to 1 .

According to probabilistic evaluation [7], the characteristic values of stress for action are greater as compared with the characteristic resistances. In the some time the failure probability is a very small one. From data presented there is clear to noted the reduced value of the failure probability. From the three phases of analysis, the bridge with two cantilevers, as original configuration, has a high probability of failure and the Koror Bridge is included into 15 structures which have to collapse. Failure probability of the concrete in the compressed zone of continuous girder, as well as the 300 bar tendons in the tension zone, have had a high probability of failure but smaller than for the two cantilever elements. 
Table 3. Probabilistic evaluation of the failure probability.

\begin{tabular}{|c|c|c|c|c|c|c|}
\hline \multirow{3}{*}{ The phase of analysis after repair } & \multirow{2}{*}{\multicolumn{2}{|c|}{$\begin{array}{l}\text { Deterministic evaluatio } \\
\text { Mean value, MPa, for: }\end{array}$}} & \multirow{3}{*}{$c_{0}=\frac{f^{r}}{f^{a}}$} & \multicolumn{3}{|c|}{ Probabilistic evaluation } \\
\hline & & & & Characteristic & e, MPa, for: & Failure \\
\hline & $\begin{array}{c}\text { Resistance } \\
f_{c}^{r} \text { or } f_{u}^{r}\end{array}$ & $\begin{array}{c}\text { Action } \\
f_{c}^{a} \text { or } f_{u}^{a}\end{array}$ & & $\begin{array}{l}\text { Resistance } \\
f_{c k}^{r} \text { or } f_{u k}^{r}\end{array}$ & $\begin{array}{c}\text { Action } \\
f_{c k}^{a} \text { or } f_{u k}^{a}\end{array}$ & $\begin{array}{c}\text { probability } \\
P_{f}, \%\end{array}$ \\
\hline 1 & 2 & 3 & 4 & 5 & 6 & 7 \\
\hline Concrete of continuous girder & 35 & 17.65 & 1.98 & 23.5 & 23.5 & 2.0 \\
\hline Concrete of two cantilever elements & 35 & 25.00 & 1.40 & 23.5 & 33.2 & 15 \\
\hline Reinforcement at top slab & 1050 & 562 & 1.87 & 704.6 & 746.9 & 3.5 \\
\hline
\end{tabular}

\section{Conclusions}

Some very important conclusions on the causes of the Koror Bridge collapse are underlined:

1) The structure with two cantilever elements is very sensitive and vulnerable; no possibility of redistribution of the efforts; a safety coefficient depending on few parameters.

2) The cantilever elements of the Koror Bridge were partial prestressed; the part near the main pier were early cracked.

3) The quality of concrete was of interior class for a prestressed concrete element.

4) The main factor of the larger deflection than that anticipated was the prestressed loss and the cracking of concrete at the top of cross-section.

5) The arrangement of tendons in the cracked top slab near main pier was with negative influence on the prestress loss.

6) If there were not repair, the bridge could be, probably, in service for 100 years.

7) The repair of the bridge was a good idea but the measures to provide the collapse were insufficient; using a system to keep together the two parts of bridge has been necessary.

Two very important aspects are to be pointed out: the prestress loss of 50\%, which was found from experimental measurements, and cracked top slab were the main factors of the large deflection; the horizontal settlement of the repaired bridge was the cause of concrete crushed near the main pier.

The analysis presented in this work is the author's assumption on the causes of Koror Bridge collapse based on the data offered by literature. Some differences between the actual values and those used in analysis have no major influence on proposed conclusions.

\section{Acknowledgements}

The author wishes to thank to the SED Editorial Board of the IABSE for the documents offered and to Dr. M. C. Tang for his useful comments.

\section{References}

[1] Tang, M.-C. (2014) The Story of the Koror Bridge. Draft for SED 14.

[2] Burgoyone, C. and Scantlebury, R. (2006) Why Did Palace Bridge Collapse. The Structural Engineer, 30-37.

[3] Bazant, Z.P., et al. (2010) Excessive Deflections of Record-Span Prestressed Box Girder. ACI Concrete International, 32, 44-52.

[4] Klein, G. (2008) Collapse of the Koror-Babeldaob Bridge. 17th Congress of IABSE, Chicago, Report, 98-99.

[5] Khal, N. (2009) Learning from Failures. Environmental, Safety and Sustainability. OEC, 1-6.

[6] STAS 10107/0-90 (1990) Design and Detailing of Concrete. Reinforced Concrete and Prestressed Concrete Structural Members, Bucuresti.

[7] Borges, J.F. and Castanheta, M. (1974) The Safety of Structures. Editura Tehnica, Bucuresti. (in Romanian) 
Scientific Research Publishing (SCIRP) is one of the largest Open Access journal publishers. It is currently publishing more than 200 open access, online, peer-reviewed journals covering a wide range of academic disciplines. SCIRP serves the worldwide academic communities and contributes to the progress and application of science with its publication.

Other selected journals from SCIRP are listed as below. Submit your manuscript to us via either submit@scirp.org or Online Submission Portal.
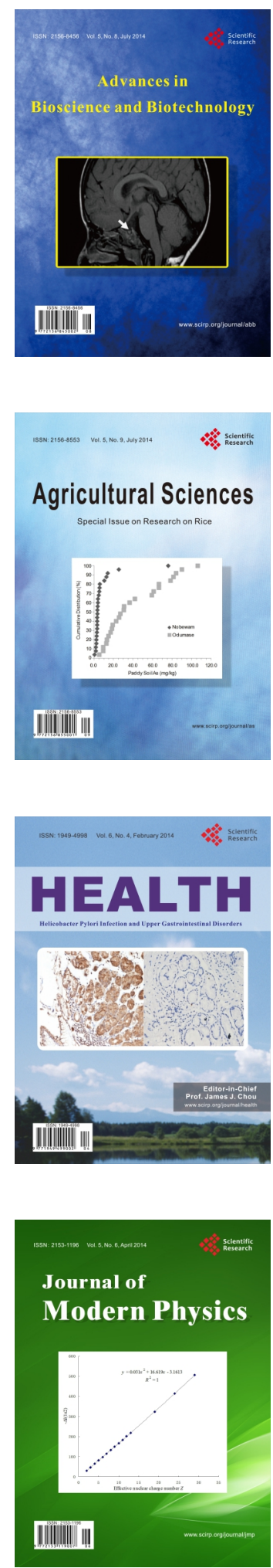
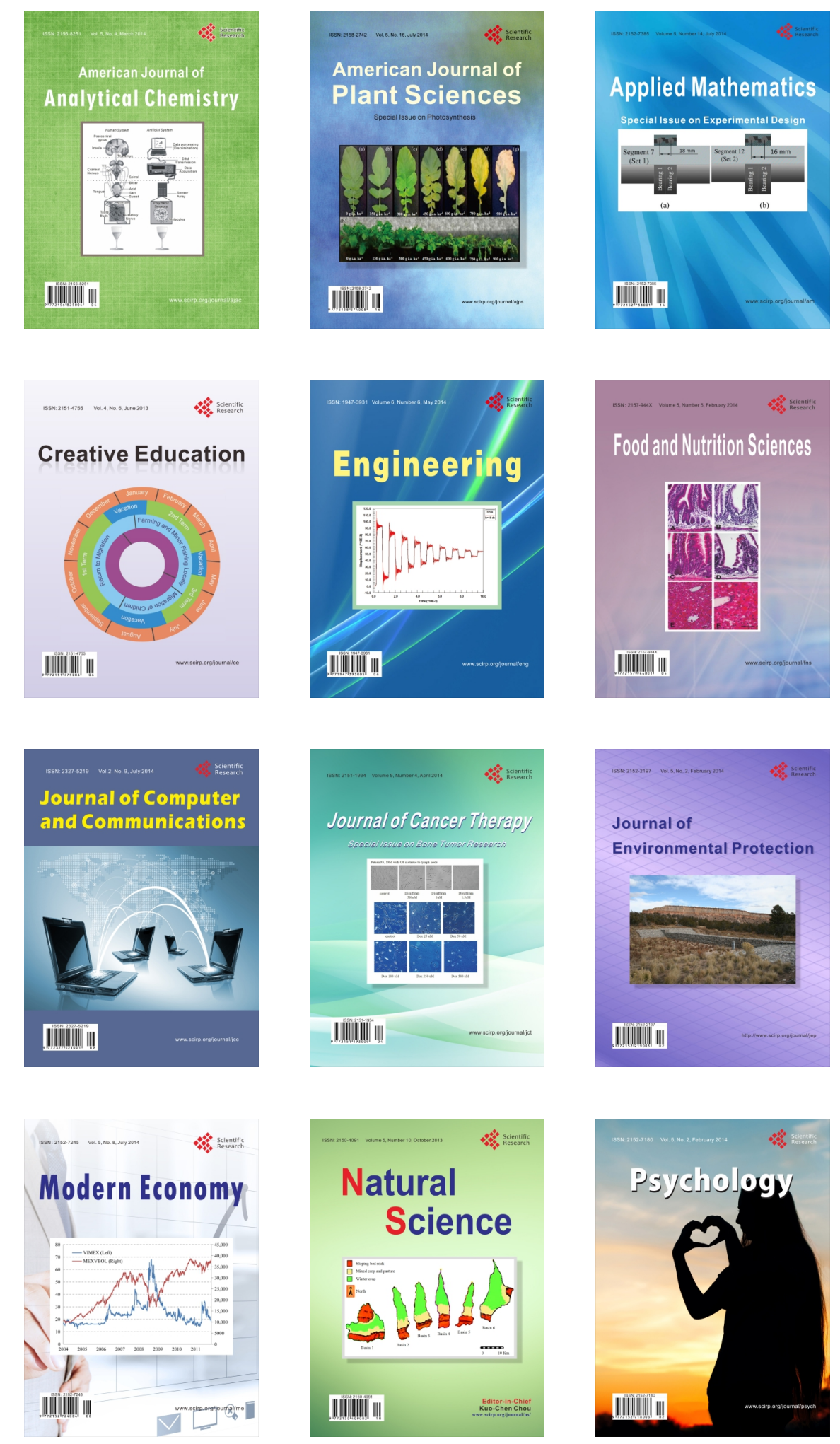